\title{
OBSERVATIONS ON POSTOPERATIIVE VOMITING*
}

\author{
F. L. SELENy, M.D., AND W. E. SPOEREL, M.D., F.R.C.P.(C)†
}

NAUSEA AND vOMITING in the postoperative period is a well-attended problem and much literature has accumulated during recent years concerning the evaluation of a group of drugs with anti-emetic properties. Almost all the anti-emetic agents known have been investigated and most of them have been advocated as being effective against postoperative nausea and vomiting. The method of investigation appeared relatively uniform; most investigators have employed the "double-blind" method in order to obtain unbiased observations for statistical evaluation.

If one compares any number of studies on postoperative vomiting, one is surprised by the wide disparity in the incidence of vomiting / in the various centres where such studies have been conducted. In a random selection of recent papers (Table I) an incidence between 60 per cent and 9 per cent was

TABLE I

Incidence of Vomiting in Eight Recent mitsigations

\begin{tabular}{|c|c|c|c|c|}
\hline Author & No. of cases & Agent & Controls, & $\begin{array}{c}\text { Treated, } \\
c \\
\end{array}$ \\
\hline $\begin{array}{l}\text { Bonica et al. }{ }^{4} 1958 \\
\text { Bellville et al. }{ }^{3}{ }^{3} 1959\end{array}$ & $\begin{array}{l}2,827 \\
2,214\end{array}$ & $\begin{array}{l}\text { Cyclizine } \\
\text { Cyclizine } \\
\text { Triftunrom }\end{array}$ & $\begin{array}{ll}60 & \\
194 \\
19 & 4\end{array}$ & $\begin{array}{l}27 \\
11 \\
9\end{array}$ \\
\hline Denson \& Elesh ${ }^{5} 1960$ & 2,362 & $\begin{array}{l}\text { Pipamazine } \\
\text { Pind }\end{array}$ & 97 & 46 \\
\hline Bellville et al., ${ }^{2} 1960$ & 345 & $\begin{array}{l}\text { Perphenazine } \\
\text { Trimethobenzamide }\end{array}$ & $\begin{array}{l}142 \\
140\end{array}$ & $\begin{array}{rl}6 & 6 \\
12 & 0\end{array}$ \\
\hline Ouellette, ${ }^{9} 1962$ & 228 & Trimethobenzanide & 263 & 143 \\
\hline Sobel, ${ }^{11} 1961$ & 110 & Trimethobenzamide & 380 & 380 \\
\hline Wolfson et al.,12 1962 & 870 & Trimethobenzamide & 394 & 356 \\
\hline Dyrberg, ${ }^{6} 1962$ & $\begin{array}{l}417(\mathrm{M}) \\
772(\mathrm{~F})\end{array}$ & Haloperidol & $\begin{array}{ll}14 & 3 \\
32 & 2\end{array}$ & $\begin{array}{rl}3 & 4 \\
10 & 8\end{array}$ \\
\hline
\end{tabular}

found. ${ }^{2-6.9 .11 .12}$ Such a wide variation leads to the assumption that different criteria have been used in regard to the observation of vomiting by the various investigators. This lack of uniform criteria makes an assessment of the magnitude of the problem of postoperative vomiting very difficult and reduces the signifcance of the reported data even if sound statistical methods have been employed.

In the studies listed in Table I, the number of patients vomiting in spite of treatment with potent anti-emetic drugs varies from 2.4 and 35.6 per cent. A reduction in the incidence of vomiting is interpreted as a significant therapeutic effect and many authors advocate the routine use of these agents in conjunction

\footnotetext{
"Presented at the Annual Meeting of the Canadian Anaesthetists' Society, Montebello, Quebec, May 14 to $17,1962$.

tDepartment of Anaesthesia, University of Western Ontario, and Victoria Hospital, London, Ontario.
} 
with anaesthesia. Such recommendations have not remained uncriticized; Keats ${ }^{7}$ felt that in 80 to 90 per cent of the surgical patients treatment with anti-emetics was unnecessary and Adriani et al. ${ }^{1}$ found vomiting severe enough to require treatment in only 3.5 per cent of their patients. An assessment of the side-effects of anti-emetic drugs is equally unsatisfactory; prolongation of recovery from anaesthesia, drowsiness, depression, hypotension, etc. have been reported and, depending on the view of the author, have been thought negligible, advantageous, or objectionable.

A recently developed agent, trimethobenzamide (Tigan), has been reported as an effective anti-emetic with almost no side-effects. This drug has been tried in various types of vomiting and reports considering the effectiveness range from excellent to poor; the criteria employed in order to arrive at these results differed from paper to paper. ${ }^{2.8-12}$

In order to get an understanding of the magnitude of the problem of postoperative vomiting in our hospital we have tried to use a different approach in an attempt to find an answer to the following questions:

1. How much of postoperative vomiting is transitory and how often is vomiting sufficiently severe to require treatment?

2. Are anti-emetic drugs, in particular trimethobenzamide, effective in controlling severe vomiting once it has commenced?

For this study we have selected patients in the recovery room who vomited twice after regaining consciousness. After the second bout of vomiting these received an intramuscular injection of an anti-emetic drug. One group of anaesthetists agreed to use trimethobenzamide routinely during the study period for all their patients that fulfilled the above criteria, while others were requested to order the anti-emetic agent of their choice for the same purpose. The following agents and dosages were used: trimethobenzamide (Tigan) $200 \mathrm{mg}$., prochlorperazine (Stemetil) $10 \mathrm{mg}$., dimenhydrinate (Gravol) $50 \mathrm{mg}$., and the cyclizine (Marzine) $50 \mathrm{mg}$, all injected intramuscularly. After the drug was given the incidence of vomiting was carefully charted by the nurse in the recovery room and for the first 48 hours postoperatively by the nurses on the ward. Only episodes of actual vomiting were recorded in this study; nausea and retching were not considered. Children under the age of 16 and patients on gastric suction were excluded.

During a period of eight months we have collected 123 cases of significant postoperative vomiting according to the above criteria, an incidence of approximately 3.6 per cent. There were 105 female and 18 male patients in this group. A comparison of the relative frequency of the type of surgery in these patients with severe vomiting and 1,000 consecutive patients selected on the same basis (i.e. no children or patients with gastric suction) is shown in Table II. The high incidence of vomiting after caesarian section and ophthalmic surgery is worth noting. Gynaecological operations have a proportionally higher incidence, while the percentage for abdominal surgery was surprisingly low. The low figure in urologic surgery reflects the frequent use of conduction anaesthesia. The main anaesthetic agents used are shown in Table III, and this distribution corresponds reasonably well with the general use of anaesthetic agents in our hospital. 
TABLE II

Slrglry in 123 Cases of Postoperative Vomiting

\begin{tabular}{|c|c|c|}
\hline Type of surgery & $\begin{array}{l}\text { io of patients with } \\
\text { postop. voriniting }\end{array}$ & $\begin{array}{c}\% \text { of } 1,000 \text { consecutive } \\
\text { patients at Victoria } \\
\text { Hospital with similar } \\
\text { types of surgers }\end{array}$ \\
\hline Gy naecology (vaginal and abdominal) & 35 & 23.0 \\
\hline Surgery in extremities & 17 & 15.4 \\
\hline Orthopaedics & 9 & 67 \\
\hline Abdominal surgery & 8 & $17 i$ \\
\hline Caesarian section & 8 & 18 \\
\hline Surgery on head and nech & 4 & 70 \\
\hline Ophthalmology & 4 & 18 \\
\hline Otorhinolaryngology & 3 & 52 \\
\hline Urology & 4 & 104 \\
\hline Surgery on the trunk & 3 & 41 \\
\hline Neurosurgery & 3 & 41 \\
\hline Proctology & 2 & 34 \\
\hline
\end{tabular}

TABLE III

Anarsthlosian 123 Cases with Postoperatile Vomitidg

\begin{tabular}{lr}
\hline Agent used for maintenance & ic \\
\hline Ciclopropane & 27 \\
Fiuothane & 39 \\
Nitrous oxide + I.V. agent & 21 \\
Ether & 3 \\
Penthrane & 3 \\
Regional & -100 \\
\hline
\end{tabular}

Premedication consisted mostly of various combinations of meperidine or morphine with atropine or hyoscine and had no detectable influence on the incidence of vomiting. Eight of the patients had received phenothiazine derivatives as premedication. The duration of surgery and the position of the patients during surgery did not reveal any contributory factors.

Of the 123 cases selected 66 were first treated with trimethobenzamide, 40 with prochlorperazine, and 9 with dimenhydrinate or cyclizine. Owing to the smaller number, we have listed the patients treated with the two latter agents under the headings "others" in our tables. The result of the treatment is shown in Table IV. Of the patients treated with trimethobenzamide 39 per cent did not vomit within a 6-hour period following the injection; of those treated with prochlorperazine 63 per cent had no further emesis. The difference is probably statistically significant. Analysis of the records of patients in whom treatment was unsuccessful showed a recurrence of vomiting more often during the first 2 hours following the treatment than during the stabsequent 4 hours. Eight patients classified as vomiting in accordance with our criteria received no anti-emetic treatment; only two had a recurrence of vomiting. Of the 115 patients treated, 37 received a second dose of an anti-emetic and 10 a third during the postoperative period.

In order to show the further course of these patients during the first 48 hours 
after operation, they were divided according to their response to the first injection of an anti-emetic agent (Table IV). Treatment was considered effective in 55 patients (see Table V). Of these, 48 received no further treatment, and in only

IABLE IV

RFSULT OF TREATMENT

\begin{tabular}{|c|c|c|c|c|c|c|}
\hline \multirow[b]{2}{*}{ Jgent } & \multirow{2}{*}{$\begin{array}{c}\text { No of patients } \\
\text { treated }\end{array}$} & \multicolumn{2}{|c|}{$\begin{array}{c}\text { Treatment effective Vo } \\
\text { recurrence of vomiting } \\
\text { within } 6 \text { hours after } \\
\text { treatment }\end{array}$} & \multicolumn{3}{|c|}{$\begin{array}{l}\text { Treatment ineffectire } \\
\gamma \text { of patients vomiting } \\
\text { after treatment }\end{array}$} \\
\hline & & $\backslash 0$ & $\%$ & $0-2$ hot & & $2-6$ hours \\
\hline I rumethoben<amide & 66 & 26 & $39^{*}$ & 30 & & 18 \\
\hline Prochlorperazine & 40 & 20 & $63^{*}$ & $10^{1}$ & & 6 \\
\hline Others & 9 & 4 & 45 & 2 & & t \\
\hline Vo treatment & 8 & 6 & 75 & 2 & & 0 \\
\hline I otal & 123 & 61 & 50 & $\pm t$ & & 28 \\
\hline
\end{tabular}

*signficant at 5 per cent level

IABLE I

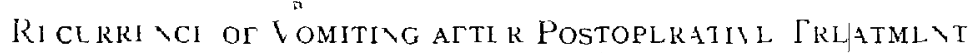
WITH A \TI-EMETIC DRLGS

\begin{tabular}{|c|c|c|c|c|c|}
\hline & & \multicolumn{4}{|c|}{$\begin{array}{l}\text { Vo of patients vominting during the following } \\
\text { time interval (hours) after the initial treatment }\end{array}$} \\
\hline & & $0-6$ & $6-12$ & $12-24$ & $21-48$ \\
\hline \multicolumn{6}{|c|}{ Ireatment eftective in 55 cases } \\
\hline$\checkmark$ further treatment & 48 & 0 & 2 & 0 & 0 \\
\hline Repeat treatment & 7 & 0 & 2 & 1 & 1 \\
\hline Fotal & 55 & 0 & $4^{*}$ & $1 \dagger$ & 1 \\
\hline \multicolumn{6}{|c|}{ Ireatment meltective $n 60$ cases } \\
\hline Vo further treatment & 30 & 30 & 6 & 2 & 3 \\
\hline Repeat treatment & 30 & 30 & 16 & 5 & $\mathrm{l}$ \\
\hline Total & 60 & 60 & $22^{*}$ & $i t$ & 4 \\
\hline
\end{tabular}

* Significant at 01 per cent level

thignificant at 5 per cent level

2 was an episode of vomiting reported during the period between 6 and 12 hours after treatment. Treatment was repeated in 4 patients for recurrence of vomiting and in 3 for nausea only. Sixty patients had a recurrence of vomiting during the first 6 hours after treatment and in these we have considered the treatment meffective. One half of this group received no further treatment. In 6 of these an episode of vomiting was recorded during the 6-12-hour period postoperatıvely after treatment, in 2 during the 12-24-hour period, and 3 vomited on the second postoperative day. In the remaining 30 patients vomiting was apparently so severe that the attending surgeon or anaesthetist felt that a repetition of the treatment with the same or another anti-emetic agent was indicated; of these 16 were still reported vomiting during the 6-12-hour period, 5 during the 12-24hour period, and one on the second day. In the 8 patients not treated initially, there was no 1ecurrence of vomiting after the 6-hour period. As indicated in 
TABLE VI

\begin{tabular}{lcc} 
Response to Repeat TREatment & With ANti-Emetic \\
\hline & No. treated & $\begin{array}{c}\text { Recurrence of } \\
\text { vomiting }\end{array}$ \\
\hline $\begin{array}{l}\text { Trimethobenzamide } \\
\text { Prochlorperazine }\end{array}$ & 9 & 7 \\
Others & 18 & 12 \\
\hline
\end{tabular}

Table VI, 37 patients had a second injection of the same or another anti-emetic. In the majority of the patients so treated, recurrent vomiting was reported in a 6-hour period following the second administration, irrespective of the drug used.

There was a slight difference in regard to the behaviour of our patients in relation to the time of administration of the an:i-emetic drug after the operation. Patients who regained consciousness rapidly and thus had their anti-emetic agent given within the first hour following surgery had a lower incidence of recurrence of vomiting after treatment than those who received their first treatment with an anti-emetic during the second or third hour after the end of the operation. Our numbers are too small to make such a difference appear significant, but it would appear to reflect to a certain extent upon the anaesthetic management.

\section{Discussion}

We are in agreement with the views presented by Keats, ${ }^{\top}$ Adriani and others, ${ }^{1}$ and Simonsen and Vandewater ${ }^{10}$ concerning the routine preoperative or intraoperative administration of anti-emetics. Whilc these drugs probably reduce the incidence of vomiting during emergence from anaesthesia, their effect on severe postoperative vomiting is less evident.

In only a small percentage of all surgical patients is vomiting severe enough to require treatment and this number would be even smaller if one applied stricter criteria for the degree of severity. ${ }^{6}$ The incidence of cases with severe vomiting diminished with an increasing time interval after surgery.

According to our observation one could divide patients with postoperative vomiting into two groups: (1) those vomiting during recovery from anaesthesia, (2) patients who persistently vomit for some time after recovery from anaesthesia.

The high incidence of vomiting reported by some investigators is most likely due to the inclusion of all patients in group 1. This was demonstrated by Dyrberg, ${ }^{6}$ who recorded the number of occurrences of vomiting in a group of 267 untreated female patients during the first 6 hours after operation. The total incidence of vomiting was 32.2 per cent; but 21.8 per cent vomited only once or twice, 4.3 per cent three or four times, while 6.1 per cent vomited over five times. By omitting group 1, one will obtain figures roughly of the same order as those reported by authors critical of the toutine use of anti-emetics ${ }^{1,6,7}$ and also approximating those reported as failures in several studies where preventive treatment was used. It appears that judicious waiting will reduce the number 
of vomiting patients quite as effectively as costly drugs. There is no good evidence that patients in whom vomiting presents a significant postoperative complication would respond better to preventive treatment than to therapy.

According to our observation, about one-half of the patients with significant vomiting responded well to anti-emetic medication; of thes: very few had a recurrence of vomiting later on. In patients where the first injection of an antiemetic drug had not controlled vomiting, subsequent treatment with the same or another agent gave unsatisfactory results. It is our impression that patients who do not respond to anti-emetic treatment deserve our special attention, since vomiting may become a complicating factor in their recovery.

The anti-emetic drugs used in this study differed in their effectiveness: prochlorperazine appeared to be superior to trimethobenzamide. In Ipatients with recurrent vomiting the effects of both drugs were disappointing. Whether the intravenous use of a higher dosage of trimethobenzamide would be effective deserves further investigation.

We did not obtain any indications of why vomiting persisted in a small number of patients. No obvious factor related to anaesthesia could be found. The high incidence of persistent vomiting after caesarian section, ophthalmic surgery, and gynaecological surgery is of interest, pointing to the possible influence of pre-existing biochemical changes or reflex action. As in many other studies, the predominance of female patients is the most significant finding and suggests perhaps constitutional or hormonal factors associated with recovery from anaesthesia and surgery that make these patients prone to vomit.

\section{SUMMARY}

We have selected 123 patients who vomited twice following complete recovery from anaesthesia; these were then treated with anti-emetic drugs. Children and patients with gastric suction were excluded. The incidence of this degree of vomiting was 3.6 per cent. Most of our patients were females. There was a higher incidence of vomiting than expected following caesarian section, ophthalmic surgery, and gynaecological operation but not after abdominal operations. The duration of the operation, the type of anaesthesia, the position of the patient, and the preoperative medication did not appear to have a significant influence. About 50 per cent of the patients did not vomit after receiving treatment. Of the two main drugs used, prochlorperazine proved to be more effective than trimethobenzamide. In patients where an initial injection of anti-ernetic had not abolished vomiting, subsequent treatment with the same drug or with another anti-emetic was less effective. Since vomiting may develop into a major postoperative complication in patients of this last group special attention should be directed to their management and these patients should be taken into consideration when the therapeutic value of an anti-emetic drug is investigated.

\section{ACKNOWLEDGMENTS}

The authors express their gratitude to their colleagues and to Mrs. Grauds and 
the nursing staff of the Recovery Room at Victoria Hospital. This study was supported by a grant-1n-aid from Hoffman LaRoche Ltd., Canada.

\section{RÉSUnÍ}

On a chorsi 123 malades qui avalent vomi delux fors après réveil complet à la suite d'une anesthésie; on les traita alors avec des anti-émétiques. Les enfants et les malades avec une succion gastrique ont été exclus de l'expérience. La fréquence des vomissements a été de 3.6 pour cent. La plupart de nos malades étaient des femmes A la suite de césariennes, de chirurgies ophtalmiques et gynécologiques, la fréquence des vomissements fut plus élevée que celle à laquelle on s'attendait, mais non après les interventions abdominales. Il ne semble pas que la durée de l'opération, le genre d'anesthésie, la position du malade et la prémédication aient exercé une influence marquée. Environ 50 pour cent des malades ne vomirent pas apres tratement. Des deux principaux médıcaments employés, la prochlorpérazine s'avéra plus efficace que la triméthobenzamide. Quand une première injection d'antı-émétıque n'a pas arrêté les vomissements, on a constaté qu'un traitement subséquent avec le même médicament, ou un autre ant1-émétique, était encore moins efficace. Comme les vomissements peuvent provoquer des complications post-opératoires sérieuses chez les malades réfractarres aux anti-émétiques, on doit les entourer de soins plus attentifs et se le rappeler quand on recherche la valeur thérapeutique d'un anti-émétique

\section{REFERENCES}

1 Adriani, J, Sumvers, F W, \& Antonx, S. O Is the Prophylactic Use of Antremetics in Surgical Patients Justified? J A M A 175: 666 (1961)

2 Bellville, J W, Bross, J. D, \& Howland, W S Post-operative Nausea and Vomitmg V. Antremetic Efficacy of Trmethobenzamide and Perphenazme Clunic Pharmacol \& Therap 1590 (1960)

3 - - The Antremetic Efficacy of Cyclizine (Marezine) and Triflupromazine (Vesprnn) Anesthesiology 20761 (1959).

4 Bontca, J. J, Crepps, W, \& Monk, B Post Anpesthetic Nausea, Retchng and Vomuting Evaluation of Cyclizine (Marezine) Suppositones for Treatment Anesthesiology 19.532 (1958).

5 Denson, J S. \& Elesh, W E A Double Blind Study of a New Antiemetic Drug, Sc-9387 Anesth \& Analg 40.430 (1961)

6 Dyrberg, V Haloperidol (Serenase) in the Prevention of Post-operative Nausea and Vomiting Acta Anaesth Scand. 6. 37 (1962).

7. KeAts, A. S. Editorial Anesthesiology 21. 213 (1960)

8 Nathan, L A Pediatric Use of Trimethobenzamide, a Specific Antremetic Curr Therap \& Research 2 6 (1960)

9 Ouellette, R D Control of Post-operative Nausea and Vomiting with Trumethobenzamide. Anesth \& Analg. 41.148 (1961).

10 Simonsen, L. E \& Vandewater, S. L. Post-operative Vomiting. A Review and Present Status of Treatment Canad. Anaesth Soc I 9 51 (1961)

11. Sobel, A Control of Post-anaesthetic Emesis with Trmethobenzamide. Anesthesiology $2492(1961)$

12. WOLFSON, B, Torres-KaY, M, \& Foldes, F. F. Investigation of the Usefulness of Trumethobenzamide (Tigan) for the Prevention of Post-operative Nausea and Vomiting Anesth \& Analg 41 172 (1962). 